\title{
Paisagem construída \\ fotografia e memória dos "melhoramentos urbanos" na cidade do Rio de Janeiro*
}

\author{
Constructed Landscape \\ Photography and Memory of the \\ 'Urban Improvements' in the City of Rio de Janeiro
}

\author{
MARIA INEZ TURAZZI \\ Historiadora, doutora em arquitetura e urbanismo pela FAU/USP \\ Pesquisadora do Museu Imperial - IPHAN/MinC \\ Museu Imperial - Rua da Imperatriz, 220 - Centro - Petrópolis /RJ - CEP 25.610-320 \\ casageyer@museuimperial.gov.br
}

\begin{abstract}
RESUMO Este artigo apresenta algumas reflexões sobre os usos sociais da fotografia na documentação das transformações urbanas na cidade do Rio de Janeiro. Desde o século XIX, a imagem fotográfica foi utilizada como recurso privilegiado para a representação visual da cidade e a criação de memórias, individuais e coletivas, das grandes obras de engenharia promovidas pelo Estado. Nos primeiros anos do século XX, esse gênero de fotografia foi essencial para a difusão de uma nova imagem da então capital federal associada aos ideais de progresso e civilização. Construída entre 1904 e 1905, a Avenida Central representou uma das principais intervenções humanas na paisagem carioca, destacando-se neste empreendimento a figura de Paulo de Frontin, engenheiro que esteve à frente de diversas obras públicas do país, entre o final do século XIX e o início do século XX.
\end{abstract}

Palavras-chaves Fotografia, Obras públicas, Rio de Janeiro

Artigo recebido em 15/10/2005. Autor convidado. 
ABSTRACT This paper presents some issues on the social uses of photography in the documentation related to Rio de Janeiro urban transformation. Since the XIX century, the photographic image has been used as a special resource for visual representation of the city and for individual and collective memory of the larger engineering works promoted by the State.In the early years of the XX century, this kind of photography was essential for the diffusion of a new image of Rio de Janeiro embedded with the ideals of progress and civilization. Built during the years 1904 and 1905, the Central avenue ("Avenida Central") represented one of the most important human interventions in Rio de Janeiro's landscape. Paulo de Frontin, an outstanding engineer, was in charge of this enterprise, as other main public works of the country he led between the end of the XIX century and the beginning of the XX.

Key words Photography, Great works, Rio de Janeiro

Desde o primeiro daguerreótipo que chegou à cidade, ainda em 1840, boa parte das imagens do Rio de Janeiro realizadas por meios fotográficos a partir de então tem registrado e difundido um dos traços mais marcantes do cenário carioca, já prenunciado em sua abundante iconografia "pré-fotográfica": a notável fusão da paisagem construída pelo homem com uma natureza monumental que enfeita e singulariza a topografia do lugar. Em mais de um século de atividade fotográfica com o registro de grandes intervenções humanas na paisagem carioca, destaca-se um expressivo contingente de "vistas urbanas" destinadas a documentar visualmente, nas primeiras décadas do século XX, as reformas na capital do país promovidas pelo governo republicano. Evidenciar a trajetória do engenheiro André Gustavo Paulo de Frontin (1860-1934) na realização dessas obras e, simultaneamente, sua atuação em favor da criação e preservação de uma memória fotográfica da Avenida Central, inaugurada em novembro de 1905, representa uma oportunidade para a discussão do papel da fotografia na documentação das transformações urbano-industriais do Rio de Janeiro, assim como no processo de institucionalização e valorização da engenharia no Brasil, entre a segunda metade do século XIX e as primeiras décadas do século XX. ${ }^{1}$

A importância crescente atribuída às imagens fotográficas, graças ao seu poder de informação e de positivação do papel do Estado na realização de obras públicas, pode ser medida, entre outros indicadores, pela

1 O presente artigo apresenta, de forma resumida, algumas questões discutidas em minha tese de doutorado, ainda inédita, intitulada As artes do ofício: fotografia e memória da engenharia no século XIX (São Paulo: Faculdade de Arquitetura e Urbanismo da Universidade de São Paulo, 1998), bem como informações que levantei mais recentemente sobre a construção da Avenida Central e o álbum produzido por Marc Ferrez, como parte de dois projetos expositivos apresentados em 2005: O Brasil de Marc Ferrez e Avenida Central 1905-2005, ambos a convite do Instituto Moreira Salles (Rio de Janeiro). Agradeço aos colecionadores e às instituições citadas pelas imagens reproduzidas neste artigo. 
também crescente encomenda de serviços fotográficos pelos agentes dessas intervenções, assim como pela contratação direta de fotógrafos por diferentes instituições públicas ou privadas desde o século XIX. Logo após os primeiros ensaios com a câmara, fotógrafos em atividade no Rio de Janeiro se associaram aos projetos modernizadores dos engenheiros que, à frente da administração municipal, de comissões, diretorias e ministérios do Império e, posteriormente, da República, comandaram as transformações urbanísticas na capital do país. Cumpria registrar em detalhes "os melhoramentos urbanos" no Rio de Janeiro e, com eles, os sinais de "progresso" e "civilização" na principal vitrine do Brasil.

Como parte integrante do processo de modernização das atividades construtivas ocorrido no período, a atividade de documentação fotográfica das obras públicas realizadas na Corte e nas províncias do Império não pode ser dissociada do processo de consolidação do Estado imperial e de construção da idéia de nação. Por outro lado, o registro visual de importantes realizações materiais do Segundo Reinado (construção de diques, estradas, ferrovias, etc.) também deve ser visto como parte integrante do processo de criação e afirmação da memória coletiva dos engenheiros, um expressivo contingente profissional empregado na administração do Estado imperial e em empresas concessionárias de serviços públicos, entre outros setores. Tendo contribuído para o "adiantamento da nação" durante o regime monárquico, engenheiros como Paulo de Frontin e outros logo seriam convocados pelo novo regime republicano para conceber e empreender as reformas urbanas tão necessárias à imagem do país e de sua capital reclamada pelos novos tempos. Nesse novo contexto, os engenheiros tornaram-se portadores de um discurso, assentado nos ideais de progresso e civilização, capaz de combinar o antigo projeto de afirmação da nacionalidade com os novos interesses e empreendimentos de uma elite cosmopolita e industrialista. ${ }^{2}$

\section{As primeiras fotografias de obras públicas no Rio de Janeiro}

Alguns dos nomes mais expressivos da história da fotografia brasileira atuaram na cidade do Rio de Janeiro testemunhando com suas lentes grandes transformações na paisagem carioca. Fotógrafos como Marc Ferrez e Augusto Malta, para citar apenas dois dos nomes mais conhecidos, deram visibilidade a novos empreendimentos urbanos, forjando através de suas imagens a identidade social e a memória profissional das primeiras gerações de engenheiros formados no país. As imagens produzidas com a contratação dos serviços desses fotógrafos contribuíram

2 Sobre o tema da "reforma da cidade" como um discurso unificador da identidade coletiva dos engenheiros durante a República Velha, ver CARVALHO, Maria Alice R. Quatro vezes cidade. Rio de Janeiro: Sette Letras, 1994, p.77 e segs. 
para a valorização social e profissional dos engenheiros e, por conseguinte, para a afirmação da chamada "engenharia nacional", termo freqüentemente empregado com o sentido de individualizar e ressaltar as realizações dos engenheiros formados no país.

O alemão Revert Henrique Klumb foi o primeiro fotógrafo em atividade no Brasil a documentar, ainda em 1860, a realização de uma grande obra de engenharia na cidade do Rio de Janeiro. Pouco tempo depois de ter chegado à capital do Império, em meados da década de 1850, Klumb foi responsável pela produção das primeiras vistas estereoscópicas da cidade, destacando-se nessas imagens o registro de edifícios públicos como o Paço Imperial e a Escola Central da Corte, entre outras vistas urbanas. Em 1860, no entanto, ele realizou fotografias de uma obra de engenharia propriamente dita, ao documentar a construção do dique Imperial, na ilha das Cobras (junto ao Arsenal de Marinha da Corte).

Obra que se arrastava desde o início do século (1824), a construção de um dique na ilha das Cobras para facilitar a limpeza e o conserto de navios atracados era um complemento necessário às instalações do Arsenal de Marinha da Corte, então uma das principais instituições brasileiras ligadas à engenharia em atividade no século XIX. O Arsenal, com suas oficinas mecânicas, operários especializados e engenheiros com formação no exterior, era responsável pela construção e reparação de navios mercantes e de guerra, um setor fundamental para a segurança do país e a defesa dos interesses territoriais, políticos e econômicos do Império. ${ }^{3}$

Em 1859, o público presente à Exposição Geral de Belas Artes promovida pela Academia Imperial já havia contemplado, pela primeira vez no Rio de Janeiro, a exibição de algumas fotografias de edificações imponentes da cidade: a própria sede da instituição, onde se realizava o evento, a igreja e o mercado da Glória, o hospital da Penitência, a igreja de Santo Antônio, o hospital da Sociedade Portuguesa de Beneficência e o aqueduto da Carioca. Essas edificações foram registradas pelo fotógrafo (possivelmente italiano) Manoel Banchieri, estabelecido no Rio de Janeiro, entre 1855 e 1864. Na exposição realizada em 1860, Klumb apresentou na Academia Imperial cerca de vinte fotografias, incluindo retratos, reproduções de esculturas, imagens estereocópicas, cartes de visite e vistas diversas da cidade, entre as quais duas imagens que mostravam o dique da ilha das Cobras, ainda em construção, tomadas do lado norte e do lado sul.

Aquelas eram as primeiras fotografias de uma obra de engenharia ainda em construção, exibidas publicamente no Rio de Janeiro. Pelo conjunto apresentado na seção destinada aos "artefatos da indústria e

3 Concluída a obra, segundo o projeto do engenheiro inglês Henrique Law, o novo dique foi inaugurado a 21 de setembro de $1861 \mathrm{com}$ a presença do imperador D. Pedro II, como era de praxe nos lançamentos de navios do Arsenal. Na ocasião, o dique foi batizado com o nome de "Imperial" e depois da Proclamação da República passou a chamar-se Dique Guanabara. 
aplicação das belas artes", Klumb recebeu uma menção honrosa. Notese que ele concorrera aos prêmios concedidos em tais ocasiões (medaIhas e menções honrosas) na condição de "fotógrafo da Academia Imperial de Belas Artes". Klumb era também o primeiro no Brasil a receber tal concessão de uma instituição pública do Império e, portanto, a contar com esse tipo de chancela oficial na promoção de seu estabelecimento fotográfico, embora outros profissionais, destacando-se como retratistas, já tivessem recebido o título de "fotógrafos da Casa Imperial". Uma década mais tarde, Marc Ferrez também seria escolhido como "fotógrafo da Marinha Imperial", título que ostentaria ao longo de sua extensa e profícua carreira, onde não foram poucos os comissionamentos para a documentação de grandes projetos de engenharia.

O aparecimento da chamada "fotografia de engenharia" nos salões de exposição da Academia Imperial de Belas Artes não era casual. O país assistia a um crescimento das atividades industriais e dos serviços de transporte, notadamente a construção das estradas de ferro que cortavam o Brasil de norte a sul. Em 1862, criava-se a Secretaria de Estado de Agricultura, Viação e Obras Públicas, instância governamental que daria impulso a essas atividades, assim como à realização de exposições industriais, expedições exploratórias, levantamentos cartográficos, entre outras obras e projetos de engenharia propriamente ditos. Nas grandes exposições nacionais realizadas no Rio de Janeiro, nos anos de 1861, 1866, 1873, 1875 e 1881, a presença significativa de imagens fotográficas representando cidades, ferrovias, expedições exploratórias e outros projetos e empreendimentos ligados à engenharia reforçava ainda mais o caráter celebrativo de tais eventos e sua importância para a divulgação no Brasil e no exterior dos progressos da nação na segunda metade do século XIX. ${ }^{4}$

\section{Paulo de Frontin e a "engenharia nacional”}

O engenheiro André Gustavo Paulo de Frontin (1860-1934) ingressou na profissão exatamente nesse período. Um dos maiores engenheiros de seu tempo, Frontin foi responsável por obras públicas que tiveram grande impacto na vida dos cariocas. Em 1874, aos 14 anos, ele entrou para a Escola Politécnica do Rio de Janeiro, instituição à qual estaria vinculado por 52 anos, primeiro como aluno e, depois, como professor, até chegar à direção da Escola, entre 1915 e 1930. Ao longo de sua carreira, Frontin teria papel determinante no desenvolvimento ferroviário do Brasil, com a elaboração de vários estudos e projetos nessa área, como construtor da E. F. Melhoramentos do Brasil e como diretor da principal ferrovia brasilei-

4 O tema foi desenvolvido mais amplamente em TURAZZI, Maria Inez. Poses e trejeitos; a fotografia e as exposições na era do espetáculo (1839-1889). Rio de Janeiro: Funarte e Rocco, 1995. 310 p., il. 
ra, a E. F. Central do Brasil. Presidente do Clube de Engenharia, entre 1903 e 1931, Frontin também exerceu o mandato de deputado e senador, sendo nomeado prefeito da cidade do Rio de Janeiro em 1919. ${ }^{5}$

A trajetória de Paulo de Frontin está, portanto, indissoluvelmente ligada ao processo de institucionalização da engenharia no Brasil nas últimas décadas do século XIX e primeiras do século $X X$, bem como à história das transformações urbano-industriais da capital do país nesse período. Por isto mesmo, trata-se de uma trajetória que concentrou, em si mesma, boa parte das conquistas e dos dilemas que cercavam a formação intelectual, a atuação profissional e a inserção social dos engenheiros de seu tempo. A imagem fotográfica, além de participar da formação e atualização dos engenheiros, também contribuía para a construção da identidade e da memória desses profissionais.

Formados pela Escola Politécnica do Rio de Janeiro e demais instituições de ensino de engenharia do país, reunidos em torno do Clube de Engenharia e outras associações profissionais, engajados em diferentes empreendimentos urbanos e industriais do período, os engenheiros contemporâneos de Paulo de Frontin, embora não possam ser vistos como um grupo homogêneo, construíram sua identidade profissional unidos por valores e práticas alicerçados em uma formação enciclopédica e polivalente. Esses engenheiros viveram o momento de maior influência e prestígio da Escola Politécnica do Rio de Janeiro, quando a instituição consagrouse como um centro de altos estudos, no qual despontaram nomes como André Rebouças, Aarão Reis, Henrique Charles Morize, entre outros. ${ }^{6}$

Com apenas 29 anos, Frontin já alcançara prestígio profissional e consagração popular, devido ao trabalho de reforço da adução de água para a cidade do Rio de Janeiro, no episódio conhecido como "água em seis dias". Vivaldo Coaracy, em um de seus artigos para a Revista do Clube de Engenharia, comentou o assunto, assinalando a recorrência da falta de água na vida dos cariocas:

Desde a época da fundação, viram-se sempre os habitantes do Rio de Janeiro a braços com o problema da água potável. Todas as administrações que se sucederam no governo da cidade com ele se preocuparam e, estimuladas pelo clamor público, procuraram dar-Ihe solução. A cidade cresce e o problema ressurge. ${ }^{7}$

5 Cf. ATHAYDE, Raymundo de. Paulo de Frontin, sua vida e sua obra. Rio de Janeiro: Secretaria Geral de Educação e Cultura, 1965; MARTINS, Luiz Dodsworth Martins. Presença de Paulo de Frontin. Rio de Janeiro: Livraria Freitas Bastos, 1966 e SILVA, Maurício Joppert da. Paulo de Frontin, o patrono da engenharia brasileira; sua vida, sua obra, sua glória. Rio de Janeiro: Ministério dos Transportes e Clube de Engenharia, 1972.

6 Cf. TELLES, Pedro Carlos da Silva. História da engenharia no Brasil (séculos XVI a XIX). Rio de Janeiro: Livros Técnicos e Científicos, 1984.

7 COARACY, Vivaldo. Velharias cariocas; antigos trabalhos de engenharia. Revista do Clube de Engenharia Separata ํㅜ 71, Rio de Janeiro, p.13, 1940. 
A questão, portanto, era antiga e foi uma das principais preocupações das autoridades do Império ao longo de toda a segunda metade do século XIX. Para enfrentá-la, vários engenheiros (André e Antônio Rebouças, Jerônymo R. de Morais Jardim, Francisco Bicalho) já haviam sido convocados pelo governo imperial, tendo como missão a tarefa de apresentar planos e projetos que pudessem ajudar a resolver o problema. Em 1889, quando o adequado abastecimento de água da cidade do Rio de Janeiro ainda continuava sem solução e era agora agravado pela falta de chuvas e o medo das epidemias, o episódio da "água em seis dias" evidenciou para os cariocas a competente atuação de Paulo de Frontin e o papel da engenharia na solução dos problemas urbanos. As matérias publicadas na imprensa, as charges e as fotografias produzidas na ocasião se encarregaram de ampliar o alcance desses acontecimentos no tempo e no espaço.

Desde 1880, o engenheiro Francisco Bicalho dirigia a Inspetoria de Águas do Município da Corte e embora já realizasse um extenso trabaIho de captação de mananciais distantes e operação do reservatório de Pedregulho (recém-construído), sua repartição só apresentava planos de execução demorada a uma população já fatigada pela falta d'água, pelas epidemias e pelo calor. ${ }^{8}$ No verão de 1889, o desespero popular traduziu-se em protestos públicos. O povo reclamava nas ruas e os políticos na imprensa, cobrando uma atitude do governo. Foi então que a Secretaria de Agricultura, Comércio e Obras Públicas do Império publicou uma nota nos jornais dando garantias ao profissional que cumprisse "o dever patriótico de vir em auxílio da administração" para realizar o "milagre" de uma solução de curto prazo. ${ }^{9}$ Criado o alvoroço, Paulo de Frontin mandou uma carta para o Diário de Notícias comprometendo-se a trazer por dia um volume de 15 milhões de litros d'água para os reservatórios da cidade, no prazo máximo de "seis dias", desde que fossem garantidos pelo governo os recursos financeiros e materiais necessários. Proposta logo aceita pelas autoridades, ainda que com cláusulas draconianas para o engenheiro. ${ }^{10}$ Maurício Joppert da Silva, ex-aluno e professor da Escola de Engenharia da Universidade Federal do Rio de Janeiro, sucessora da antiga Escola Politécnica, descreveu com visível entusiasmo o sucesso alcançado por Frontin naquela ocasião:

8 O engenheiro Pedro C. da Silva Telles esclarece: "apesar do grande progresso que representava, o sistema de abastecimento d'água tinha o defeito de ser extremamente vulnerável em relação às variações sazonais de vazão dos mananciais, pelo fato de não existirem barragens com reservatórios reguladores nos pontos de captação; somente a adutora do rio do Ouro tinha uma bacia de acumulação. Com isso, nos anos de fortes estiagens [como no verão de 1888/1889] o abastecimento d'água da cidade ficava seriamente prejudicado". TELLES, Pedro Carlos da Silva. História da engenharia no Brasil, p.284.

9 Jornal do Commercio, 10 de março de 1889.

10 A estratégia empregada por Frontin consistiu no desvio e na canalização provisória das águas da serra do Tinguá, usando como mão de obra o pessoal da Estrada de Ferro do Rio d'Ouro. Além de pesadíssima multa para cada dia de atraso, não se previa qualquer imprevisto ou falha do próprio governo. TELLES, Pedro Carlos da Silva. História da Engenharia no Brasil, p.184 e SILVA, Maurício Joppert da. Paulo de Frontin, o patrono da engenharia brasileira; sua vida, sua obra, sua glória, p.13. 
Foi uma verdadeira empreitada de formigas, em que todos trabalhavam ao mesmo tempo, cada um desempenhando sua tarefa, nada faltando, desde o material necessário até a comida para o pessoal técnico. E acima de tudo, enfrentavase a malquerença do pessoal do governo e da Inspetoria de Águas. Paulo de Frontin, incansável, movimentava-se ao longo de toda a obra, coordenando os serviços para que tudo corresse bem. E correu, felizmente, porque no dia 23, isto é, seis dias depois da partida do Rio, estavam as obras terminadas e aceitas, medindo-se na caixa do Barrelão o volume diário de 16 milhões de litros. ${ }^{11}$

O famoso episódio da "água em seis dias", como o caso ficou conhecido na imprensa da época e na historiografia sobre o tema, conferiu não somente popularidade e reconhecimento público a Paulo de Frontin. Ele também parece ter dado ao engenheiro a convicção de que a visibilidade dos "melhoramentos urbanos" era estratégica para a valorização do papel do Estado e de seus agentes como promotores do bem-estar coletivo e do progresso material da nação. O período de quase três décadas em que Paulo de Frontin esteve à frente do Clube de Engenharia também coincide com a época na qual a entidade teve grande destaque na sociedade brasileira encarnando, como talvez nenhuma outra associação profissional tenha chegado a fazê-lo com tanta ênfase, a união entre "ciência" e "indústria" em favor do desenvolvimento do país. Elaborando pareceres e consultas técnicas de alta relevância, promovendo congressos e exposições nacionais ou internacionais, participando ativamente das reformas urbanas empreendidas no Rio de Janeiro e em outras cidades do Brasil, vários membros do Clube conquistaram postos-chaves em diferentes esferas de poder.

Criado no Rio de Janeiro, em 1880, o Clube de Engenharia trouxe para as suas fileiras engenheiros do Brasil e do exterior, assim como industriais, políticos e negociantes de várias partes do país, reunidos em torno de uma associação profissional concebida para ser não somente um clube de engenheiros, mas uma instituição a "serviço da engenharia" e do "engrandecimento da pátria pelo trabalho". ${ }^{12}$ Os primeiros dirigentes do Clube, depois de obterem junto ao governo imperial a aprovação do estatuto e do regimento interno da entidade, passaram o cargo para uma nova diretoria, em 1881, manifestando a convicção de que

a utilidade da nossa associação vai sendo reconhecida e apreciada cada vez mais. Colocados em esfera superior e encarando somente as necessidades da indústria em geral, promovendo nas raias de nossas atribuições, os melhoramentos reclamados para o bem do país, o Clube de Engenharia há de justificar cada vez mais os aplausos da opinião. ${ }^{13}$

11 SILVA, Maurício Joppert da. Paulo de Frontin, o patrono da engenharia brasileira, p.13-14.

12 Revista do Clube de Engenharia, Rio de Janeiro, 1887, p.2.

13 HONORATO, Cesar Teixeira (coord.). O Clube de Engenharia nos momentos decisivos da vida do Brasil. Rio de Janeiro: Clube de Engenharia, 1996, p. 33. 
À frente do Clube de Engenharia, como presidente da entidade, o engenheiro Paulo de Frontin seria convocado pelo novo governo republicando para comandar uma das principais intervenções urbanas na capital federal.

\section{Uma obra monumental}

Em 1903, Paulo de Frontin foi nomeado pelo presidente Rodrigues Alves para chefiar a Comissão Construtora da Avenida Central, subordinada ao Ministério da Indústria, Viação e Obras Públicas. Tratava-se não apenas de uma obra de engenharia, como também de um dos maiores e mais importantes projetos do governo republicano em sua estratégia de "sanear" e "embelezar" a capital federal como "elemento primordial para o reerguimento da vida econômica do país". ${ }^{14}$ Integrando as primeiras gerações de urbanistas que atuaram nas cidades brasileiras, Frontin estaria à frente de um empreendimento que pode ser considerado como a primeira intervenção maciça do Estado na reorganização do espaço urbano e em suas estruturas econômicas e sociais. A construção da Avenida Central, nos primeiros anos do século XX, representava um profundo corte no centro histórico do Rio de Janeiro e a introdução de um novo modelo urbanístico que, não apenas se impôs sobre o antigo traçado colonial da capital federal, como serviu de modelo para muitas outras cidades brasileiras. ${ }^{15}$

No acervo deixado pelo engenheiro Paulo de Frontin, encontram-se imagens fotográficas produzidas por João Martins Torres, nome pouco conhecido da história da fotografia no Rio de Janeiro, embora a qualidade de sua obra fale por si. Torres documentou cada etapa das obras de construção da Avenida Central e diversas solenidades realizadas entre 1904 e 1905 (início oficial das obras, inauguração do traçado, inauguração da avenida, etc). A presença dessas fotografias no arquivo do engenheiro Paulo de Frontin, hoje preservado por seus descendentes, levanta a hipótese de que elas possam ter sido encomendadas pela referida Comissão, instância subordinada ao Ministério da Indústria, Viação e Obras Públicas, uma vez que a Comissão também promoveu a edição do álbum de feições monumentais realizado por Marc Ferrez.

Maior fotógrafo brasileiro de sua época, cuja produção está intimamente associada à imagem do Rio de Janeiro entre a segunda metade do século XIX e início do século XX, Ferrez foi também o profissional que mais produziu fotografias de obras de engenharia ao longo desse perío-

14 Mensagem do Presidente Rodrigues Alves ao Congresso Nacional, 1903.

15 Ver CHIAVARI, Maria Pace. As transformações urbanas no século XIX. In: BRENNA, Giovanna Rosso Del (org.). O Rio de Janeiro de Pereira Passos: uma cidade em questão II. Rio de Janeiro: Index, 1985. 
do. Nessas imagens, ele registrou com sensibilidade e apuro formal não somente as obras que se faziam na Corte, como também aquelas que se espalhavam pelo restante do país. Como fotógrafo da Marinha Imperial e da Comissão Geológica, Ferrez realizou várias viagens pelo Brasil, sobretudo nas décadas de 1870 e 1880. Nessa época, ele percorreu o país de norte a sul fotografando, por exemplo, a São Paulo Railway Company (a Santos-Jundiaí), a Estrada de Ferro Paranaguá-Curitiba, a Estrada de Ferro Teresa Cristina (Santa Catarina) e a Estrada de Ferro D. Pedro II (Rio-Minas). Na região norte-nordeste, ele também fez fotografias no Amazonas, em Pernambuco e na Bahia. No Rio de Janeiro, entre tantas vistas e panoramas da cidade, Ferrez registrou o sistema de abastecimento d'água instalado no morro do Pedregulho e a estrada de ferro do Corcovado, bem como a sede da Estrada de Ferro D. Pedro II e o prédio da Secretaria de Estado dos Negócios da Agricultura, Comércio e Obras Públicas do Império. ${ }^{16}$

Em setembro de 1903, foram iniciadas as desapropriações de imóveis no centro do Rio para a construção da Avenida Central. Estabelecido em um trecho da Rua São José por onde passaria a nova avenida, Marc Ferrez recebeu do governo, como outros proprietários, uma proposta de indenização do imóvel a ser demolido. Em 1904, ele e a esposa assinaram então "a escritura de acordo e composição amigável" com a Comissão Construtora da Avenida Central, representada por seu presidente, o engenheiro Paulo de Frontin, relativa a essa desapropriação. 0 casal recebeu 25 contos de réis pela propriedade e a indenização serviria para custear a reabertura do estabelecimento de Ferrez em um outro ponto, na mesma Rua São José, não alcançado pelo chamado "botaabaixo". Ao todo, seriam desapropriados e demolidos mais de seiscentos imóveis para a abertura da Avenida Central.

$\mathrm{Na}$ cidade de Paris, grandes obras de engenharia e arquitetura do século XIX, como a construção do teatro Opera, da torre Eiffel e do Grand Palais, foram documentadas passo a passo por eminentes fotógrafos da época (Durandelle, Petit, etc). Essas imagens compunham álbuns monumentais que celebravam as realizações da arquitetura e da engenharia francesas, sendo exibidos com destaque nas exposições universais. É bastante provável que Ferrez conhecesse esses álbuns, tendo ele mesmo visitado essas exposições e realizado com sua própria câmara várias fotografias e álbuns do gênero para as ferrovias brasileiras, como já foi apontado anteriormente. Mas o álbum da Avenida Central produzido por Ferrez, embora tenha se inspirado nesses outros empreendimentos fotográficos, tinha características singulares, podendo ser considerado, no seu gênero, único no Brasil.

16 Cf. TURAZZI, Maria Inez. Marc Ferrez. São Paulo: Cosac \& Naify, 2000. 
Os projetos arquitetônicos previstos para a Avenida Central, depois de reproduzidos por Ferrez, seriam impressos em zincografia e as fachadas de todos os edifícios, depois de serem igualmente fotografadas, seriam reproduzidas em fotogravura. Estima-se que Ferrez tenha iniciado a realização de seu álbum em 1905 e que até 1907 ele tenha produzido a maior parte das reproduções de plantas arquitetônicas e, sobretudo, das fotografias de fachadas dos edifícios já prontos (as fachadas que não estavam concluídas até meados de 1907 não chegaram a ser fotografadas por ele). Nas fontes pesquisadas, há um compromisso firmado entre Ferrez e a Comissão Construtora da Avenida Central, datado de 30 de janeiro de 1907, no valor de 3:500\$000 (três contos e quinhentos mil réis), para a impressão, "segundo um acordo prévio já estabelecido", de "um milheiro de cópias" para cada uma das trinta e cinco folhas, de tamanho $40 \times 50 \mathrm{~cm}$, com as fotogravuras relativas aos duzentos e dez blocos de impressão em poder do fotógrafo. ${ }^{17}$

Pouco tempo depois, o fotógrafo enviou uma proposta à Comissão com "a lista completa dos prédios cujas fachadas restava fotografar e mandar imprimir um milheiro de cópias na Europa". Os custos de produção dos negativos de vidro com a fachada dos prédios já concluídos, de reprodução dos projetos arquitetônicos das fachadas dos edifícios que ainda não estavam prontos e de impressão na Europa das imagens que comporiam o álbum da Avenida Central chegavam a 17 contos e 825 mil réis, uma soma vultosa para a época (para se ter uma idéia, basta compará-la ao valor da indenização recebida pelo casal Ferrez, relativa ao imóvel na Rua São José). Paulo de Frontin, como engenheiro-chefe da Comissão Construtora da Avenida Central, era o responsável pela aprovação de todos os custos ligados ao empreendimento, aí incluídos os custos desse projeto fotográfico e editorial, sendo legítimo supor, portanto, que todo o trabalho de Ferrez tenha sido alvo de suas atenções e prioridades na condução da obra. A grandeza do projeto editorial deveria corresponder, pelos indícios encontrados, à monumentalidade da obra de engenharia.

O álbum Avenida Central: 8 de março de 1903 - 15 de novembro de 1906, de Marc Ferrez, só concluído em fins de 1907, foi então distribuído a autoridades e instituições, como atestam hoje os exemplares da obra que podem ser encontrados em acervos públicos e privados. Vários exemplares da publicação, no entanto, ficaram estocados no porão da residência dos Ferrez, situada à Rua 2 de Dezembro, nas proximidades da praia do Flamengo. Em 1913, uma grande ressaca no Rio de Janeiro

17 As informações sobre a Comissão Construtora da Avenida Central e os trabalhos realizados por Marc Ferrez e outros profissionais para esse notável empreendimento encontram-se no Arquivo Nacional, em um fundo documental específico já inventariado e organizado pela instituição. 
provocou a invasão do imóvel pela água e destruiu a maior parte dos livros que se encontravam no local. Em 1982, o historiador Gilberto Ferrez, em parceria com o arquiteto Paulo Santos realizou uma primorosa reedição do álbum de Marc Ferrez, sendo o original exibido ao público na mesma ocasião. ${ }^{18}$

Embora não tenha sido possível encontrar nos documentos relativos à Comissão Construtora da Avenida Central o ponto de partida desse imenso empreendimento editorial, verificou-se ali a existência de uma extensa correspondência entre o fotógrafo e os engenheiros responsáveis pelo andamento e supervisão das obras, entre os quais destacase, naturalmente, a figura de Paulo de Frontin. Essa documentação não nos esclarece a quem devemos atribuir a iniciativa de realizar um álbum fotográfico de todas as plantas e fachadas da Avenida Central, impresso e encadernado com grande sofisticação, mas ela nos informa com riqueza de detalhes que o álbum Avenida Central: 8 de março de 1903 - 15 de novembro de 1906l, de Marc Ferrez, não foi custeado pelo estabelecimento do fotógrafo, como muitas vezes se pensou, mas sim pelo governo republicano, através do Ministério da Indústria, Viação e Obras Públicas. Trata-se, portanto, de uma informação relevante sobre esse gênero de documentação fotográfica, pois confirma a idéia de que os engenheiros brasileiros há tempos estavam conscientes da importância crescente da fotografia, de seu poder de informação e de positivação do papel do Estado, de suas singularidades na criação e preservação de memórias.

Como prefeito da cidade (1919), Frontin ainda realizaria outras obras de grande envergadura no Rio de Janeiro, como o alargamento e a construção da muralha da Avenida Atlântica, a construção das avenidas Rio Comprido (atual Paulo de Frontin), Delfim Moreira e Vieira Souto, a perfuração do túnel João Ricardo, a construção do cais da Urca e o saneamento da Lagoa Rodrigo de Freitas. Nesse período, são as fotografias de Augusto César Malta de Campos (1864-1957) que registram em maior número suas intervenções na fisionomia da cidade. Malta foi, certamente, o mais atuante, prolixo e longevo fotógrafo da primeira metade do século XX. Sua produção, iniciada pouco depois de 1900, estende-se até quase a data de sua morte e contempla, sobretudo, a realização de fotografias para a Prefeitura Municipal, onde foi admitido, em 1903, como fotógrafo da Diretoria de Obras e Viação. O posto, até então inexistente, foi criado pelo prefeito Pereira Passos especialmente para Augusto Mal-

18 Cf. FERREZ, Marc. Avenida Central: 8 de março de 1903 - 15 de novembro de 1906. Rio de Janeiro, [1907]; FERREZ, Marc. O álbum da Avenida Central; um documento fotográfico da construção da Avenida Rio Branco, 1903-1906. São Paulo: Ex-Libris / João Fortes Engenharia, 1982. Introdução de Gilberto Ferrez e estudo de Paulo F. Santos (reedição do álbum original); MUSEU NACIONAL DE BELAS ARTES. Registro fotográfico de Marc Ferrez da construção da Avenida Rio Branco. Rio de Janeiro, 1981. 
ta e este só se aposentou do serviço público em 1936. Malta ainda realizou serviços fotográficos para empresas como a Light \& Power e figuras proeminentes da sociedade carioca, além de distribuir suas fotos para as principais publicações ilustradas do Rio de Janeiro e realizar imagens de sua própria escolha e predileção.

\section{Considerações finais}

As biografias de engenheiros famosos surgiram em meados do século XIX com o objetivo, justamente, de contribuir para o fortalecimento da memória e da identidade coletiva desses profissionais, para a valorização e o reconhecimento social do papel do engenheiro. No Brasil, onde os estudos sobre a história da técnica e da tecnologia ainda são pouco numerosos, encontram-se com relativa facilidade biografias dos nomes que mais se destacaram na "engenharia nacional": André Rebouças (1838-1898), Pereira Passos (1836-1913), Paulo de Frontin (1860-1934), Aarão Reis (1853-1936), para citar apenas alguns engenheiros mais conhecidos que tiveram suas vidas e carreiras biografadas em publicações de cunho diverso (livros de editoras comerciais, publicações institucionais, artigos em revistas técnicas e jornais de grande circulação, etc.)

As duas biografias do engenheiro Paulo de Frontin publicadas na década de 1960, assim como muitas homenagens que Ihe foram prestadas (a antiga cidade de Rodeio, no estado do Rio de Janeiro, por exemplo, foi rebatizada com o seu nome), não deixavam de ter, a seu modo, essas mesmas características e objetivos. Elas integravam um conjunto de iniciativas pessoais e institucionais voltadas para a valorização dos engenheiros e a preservação da memória da engenharia e da indústria no Brasil. Nas últimas décadas, no entanto, esse gênero de iniciativa enfrentou grandes dificuldades e um certo desinteresse, em que pese a importância dos acervos documentais ligados aos engenheiros e suas entidades, bem como a imponência do patrimônio urbano-industrial herdado dos séculos XIX e XX. Espera-se que este artigo contribua para estimular o interesse e renovar a reflexão sobre a importância das fotografias de engenharia para a história urbana. 


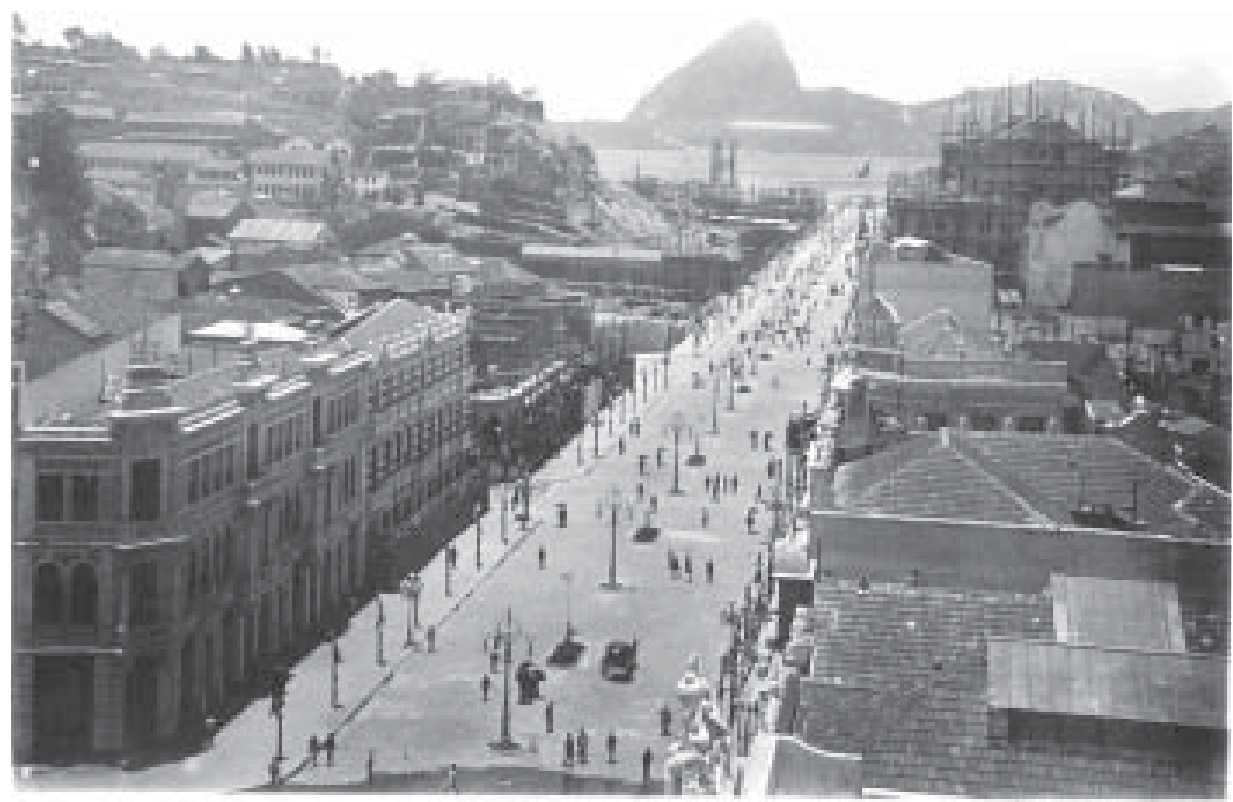

A Avenida Central, em direção às obras da orla, na Praia de Santa Luzia, tomada de um edifício nas proximidades da Rua da Assembléia. A construção da Escola Nacional de Belas Artes e da Biblioteca Nacional, à esquerda, aos pés do Morro do Castelo, estava em fase inicial. Á direita, a construção do Teatro Municipal, em fase mais adiantada. Fotografia de João Martins Torres, 1905-1906 - Coleção Álvaro de Frontin Werneck

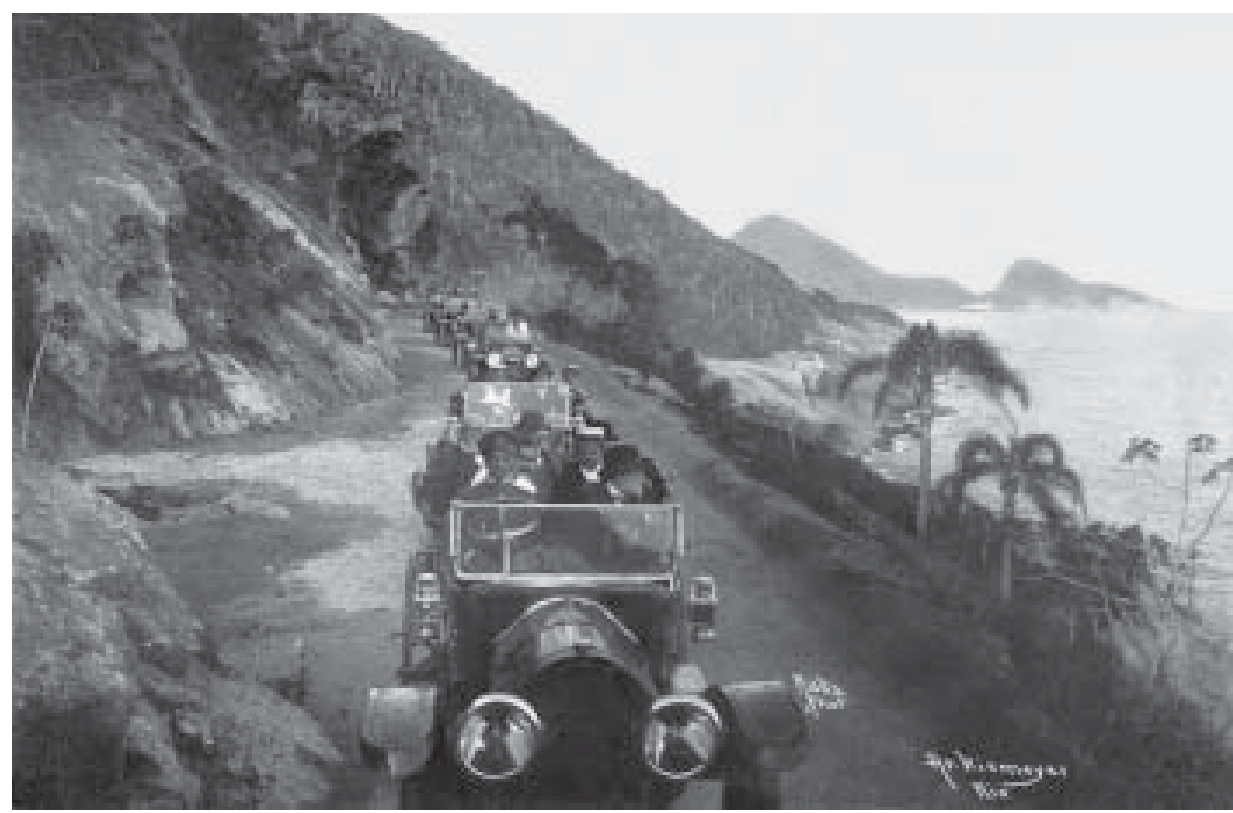

A abertura da Avenida Niemeyer, na gestão do prefeito Paulo de Frontin (o primeiro, à direita), obra que ampliaria a expansão da cidade em direção às praias oceânicas. O empresário Conrado Jacob Niemeyer (o primeiro, à esquerda, na terceira fila), era um dos fundadores do Clube de Engenharia (1880). Fotografia de Augusto César Malta de Campos "Avenida Niemeyer, 1919". Coleção George Ermakoff 


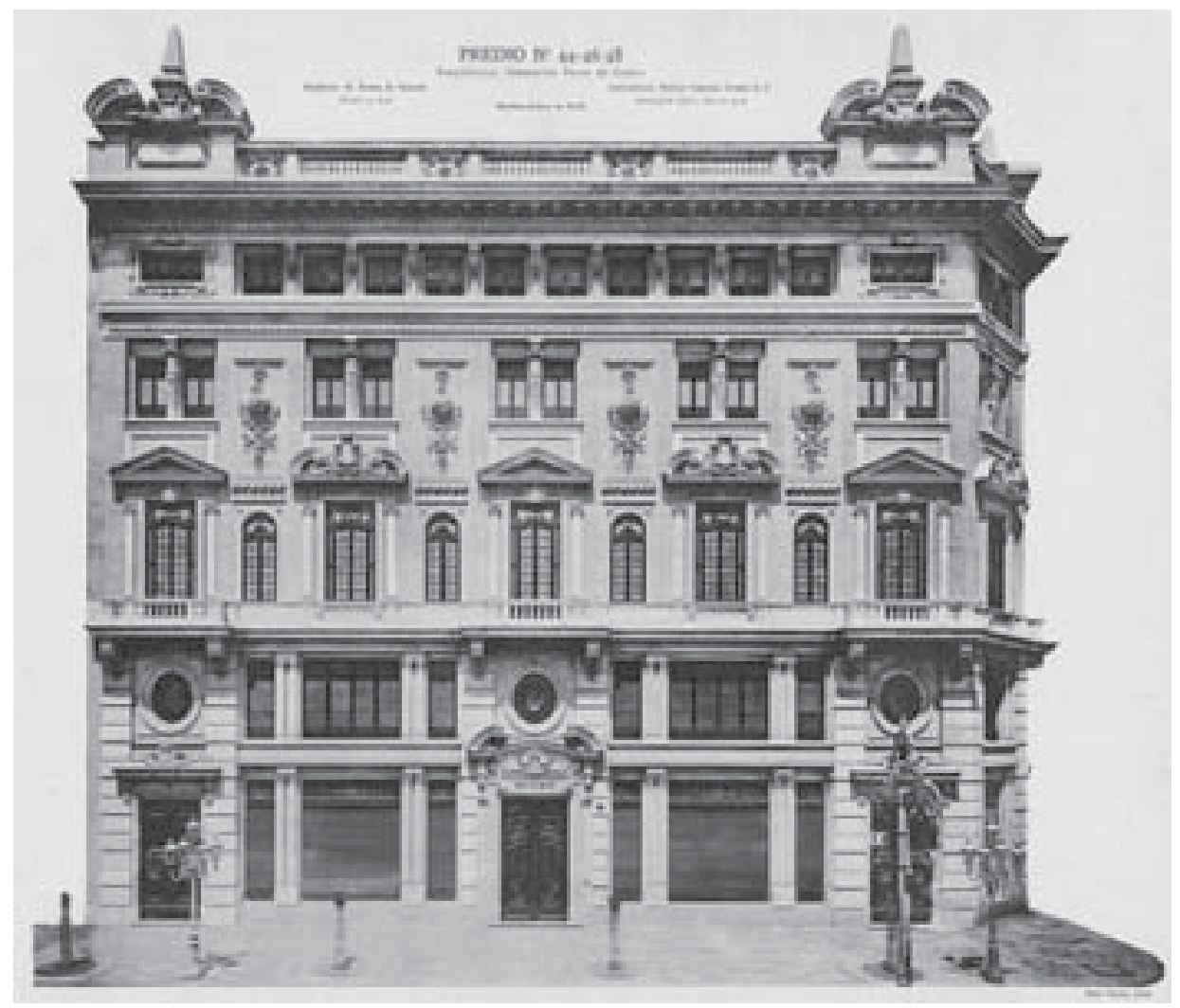

A fachada do edifício da Companhia Docas de Santos, projetado pelo arquiteto Ramos de Azevedo. Fotografia de Marc Ferrez, impressa em fotogravura, para o álbum Avenida Central - 8 de março de 1903 - 15 de novembro de 1906. Acervo Biblioteca de Obras Raras do Centro de Tecnologia da UFRJ.

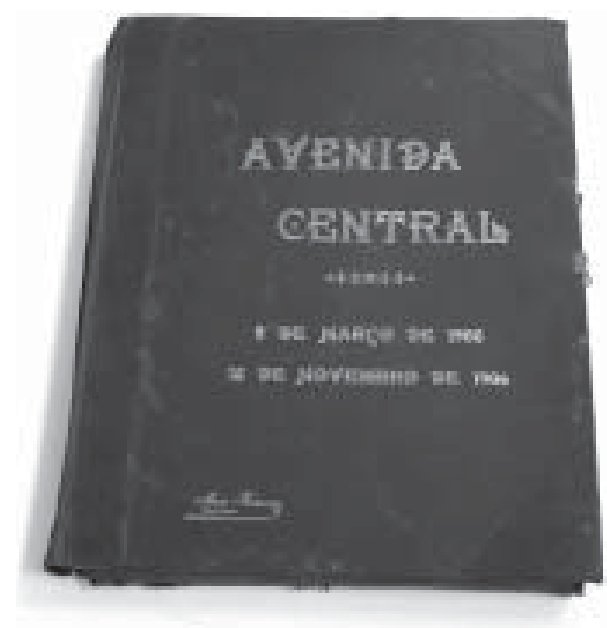

Exemplar do álbum Avenida Central - 8 de março de 1903 - 15 de novembro de 1906 , de Marc Ferrez. Encadernação em forma de pasta, contendo as pranchas com as reproduções das plantas arquitetônicas e as fotogravuras com as fachadas dos edifícios. Fotografia de Jaime Acioli Acervo Biblioteca de Obras Raras do Centro de Tecnologia da UFRJ. 